\title{
Organizadores prévios no processo de ensino de Física: o que dizem os periódicos da área
}

Advance organizers in the Physics teaching process: What do journals in the field say

Ingridy Loreian ${ }^{1}$

Luiz Marcelo Darroz ${ }^{2}$

Cleci Teresinha Werner da Rosa ${ }^{3}$

\section{Resumo}

A investigação relatada buscou identificar, na produção científica brasileira, os materiais utilizados como organizadores prévios em propostas que visam promover aprendizagens significativas de conceitos físicos. Mais especificamente, aborda-se o modo como a aplicação de organizadores prévios no processo de ensinar Física é apresentada em artigos de periódicos nacionais com Qualis A1 e A2, disponíveis on-line no sistema de avaliação da Capes, Área de Ensino, entre o ano de 2008 e o primeiro semestre de 2019. Dos artigos encontrados, seis continham a expressão "organizadores prévios" no título, resumo e/ou nas palavras-chave, sendo incluídos no estudo. Todos foram analisados e classificados considerando os materiais utilizados como organizadores prévios e a sua aplicação no ensino de Física. Como resultado, verificou-se a predominância do uso de recursos tecnológicos para esse fim.

Palavras-chave: Organizadores prévios; ensino de Física; Teoria da Aprendizagem Significativa; aprendizagem significativa.

\section{Abstract}

The investigation reported sought to identify, in the Brazilian scientific production, the materials used as advance organizers in proposals that aim to promote the meaningful learning of Physics concepts. More specifically, this study addresses how the use of advance organizers in the Physics teaching process is presented in Brazilian journals, with Qualis $A 1$ and $A 2$, available online in the Capes (Coordination for the Improvement of Higher Education Personnel) evaluating system, Field of Education, between the year 2008 and the first semester of 2019. From the articles found, six had the term "advance organizers" in the title, abstract, and/or keywords and were included in the research. All articles were analyzed and classified considering the materials used as advance organizers and their application in Physics teaching. As a result, the predominant use of technological resources for such purpose was verified.

Keywords: Advance organizers; Physics teaching; Meaningful Learning Theory; Meaningful learning.

\footnotetext{
${ }^{1}$ Universidade de Passo Fundo |166795@upf.br

${ }^{2}$ Universidade de Passo Fundo | Idarroz@upf.br

3 Universidade de Passo Fundo | cwerner@upf.br
} 


\title{
Introdução
}

A Física é a ciência que se destina ao estudo da natureza e seus fenômenos. Busca a compreensão científica dos comportamentos naturais e gerais do mundo que nos cerca, por meio de métodos científicos, da lógica, da reflexão crítica, tendo a matemática como linguagem por excelência (DARROZ; TREVISAN; ROSA, 2018). O avançO nesta ciência contribuiu de forma inestimável para o desenvolvimento de toda a tecnologia moderna, desde o automóvel até os computadores quânticos (CHAVES; SHELLARD, 2005).

No entanto, paradoxalmente, o ensino da Física em nível médio está em crise. De acordo com Moreira (2018, p. 71),

\begin{abstract}
a carga horária semanal destinada ao estudo dos conceitos físicos, que chegou a ser de seis horas-aula por semana, hoje é de duas horas ou menos. Aulas de laboratório praticamente não há. Faltam professores da área nas escolas, e os que existem são obrigados a treinar os alunos para as provas, para as respostas corretas, em vez de ensiná-los a pensar fisicamente. Os conteúdos curriculares não vão além da mecânica clássica e são abordados da maneira mais tradicional possível, totalmente centrada no professor.
\end{abstract}

Conforme o autor, o resultado desse ensino é que os estudantes, no lugar de desenvolverem uma predisposição para aprender Física, como seria esperado para uma aprendizagem significativa, geram uma indisposição tão forte que chegam a dizer que "odeiam" a disciplina (MOREIRA, 2018, p. 73).

Buscando contrapor a realidade que ora se verifica, diversos trabalhos apresentam metodologias de ensino voltadas a melhorar a aprendizagem daqueles que frequentam a escola. Nesse contexto, a Teoria da Aprendizagem Significativa (TAS), de David Paul Ausubel, tem sido a principal fundamentação para as propostas que visam promover aprendizagens significativas.

De modo geral, a aprendizagem preconizada pela TAS caracteriza-se pela interação entre o novo conhecimento e o conhecimento prévio, em que os novos significados adquiridos servem para enriquecer os já existentes, elaborando assim, cada vez mais, os conceitos estudados. Para facilitar essa interação, Ausubel (1980 apud MOREIRA, 1999) salienta a necessidade de iniciar o processo de ensino identificando o que os aprendizes já sabem, para então ensiná-los de acordo. No entanto, o teórico afirma que, quando o aprendiz não dispõe de conhecimentos adequados que the permitam atribuir significados aos novos conhecimentos, é necessário recorrer a organizadores prévios.

Segundo Moreira (1999), o organizador prévio consiste em um recurso instrucional apresentado em um nível mais alto de abstração, generalidade e inclusividade em relação ao material de aprendizagem. Ele explica que esses materiais não correspondem a um sumário ou um resumo, que geralmente estão no mesmo nível de abstração do material a ser aprendido, mas se referem a um enunciado, uma pergunta, uma situação-problema, uma demonstração, um filme, uma leitura introdutória, uma simulação ou uma aula que precede um conjunto de outras aulas. Ou seja, são materiais que precedem a apresentação do material de aprendizagem propriamente dito, sendo mais abrangentes, mais gerais e inclusivos do que ele (MOREIRA, 1999).

Stone (2015), num estudo sobre as contribuições dos organizadores prévios para a aprendizagem, demonstrou que a utilização de organizadores avançados promove um 
significativo aumento da aprendizagem e da retenção do material a ser aprendido. Na mesma direção, Cutrer et al. (2012) salientam que os organizadores prévios são ferramentas educacionais que ajudam a conectar o conhecimento prévio a novas informações. Os autores indicam a utilização de mapas conceituais como organizadores prévios, por permitirem uma aprendizagem mais profunda e significativa, melhorando a integração do conhecimento.

Frente a esse contexto, em que o uso de organizadores prévios auxilia na promoção de aprendizagens significativas tão necessárias no contexto atual do ensino de Física, surgem as seguintes indagações: que materiais vêm sendo utilizados como organizadores prévios nos trabalhos que objetivam a promoção de aprendizagens significativas no ensino de Física? Como esses materiais têm sido aplicados no processo de ensinar conceito físicos?

$\mathrm{Na}$ busca de respostas para essas perguntas, elege-se como objetivo deste estudo investigar, junto aos periódicos nacionais mais expressivos da área de Ensino de Física/Ciências, os materiais que vêm sendo utilizados como organizadores prévios, verificando de que modo ocorre sua aplicação no processo de ensino de conceitos da disciplina.

Nessa perspectiva, o trabalho estrutura-se da seguinte forma: na próxima seção, é apresentada sucintamente a TAS; na sequência, descreve-se a metodologia desenvolvida na pesquisa; a seguir, divulgam-se os resultados alcançados; e, no encerramento, expõem-se as considerações finais.

\section{A Teoria da Aprendizagem Significativa}

A Teoria da Aprendizagem Significativa, proposta por David Paul Ausubel (1918-2008), foi desenvolvida a partir dos anos 1960, e seus estudos prosseguiram nas décadas seguintes. $\mathrm{Na}$ concepção de seu autor, a aprendizagem não está relacionada ao simples ato de memorização, mas ocorre quando o conhecimento interage com a estrutura cognitiva do aprendiz, tornando-se significativo para ele (AUSUBEL, 1978).

Tal teoria fundamenta-se no cognitivismo, isto é, parte da elaboração do conhecimento, processo em que a vivência e a experiência de cada indivíduo não podem ser ignoradas. Nessa direção, Ausubel (1978, p. iv) salienta: "Se tivesse que reduzir toda a psicologia educacional a um só princípio, diria o seguinte: o fator isolado mais importante influenciando a aprendizagem é aquilo que o aprendiz já sabe. Determine isso e ensine-o de acordo".

Silva e Schirlo (2014) destacam que, de acordo com a TAS, o aprendiz possui um conhecimento sobre algo que, organizado na sua mente, deve interagir com o conhecimento novo. Todo conhecimento, portanto, deve ancorar-se em elementos já presentes na estrutura cognitiva, compreendida como o conjunto total de conteúdos e de ideias organizadas naquela área particular de conhecimento. Esses conhecimentos específicos que podem ser utilizados como ancoradouros são nomeados de "subsunçores" (SILVA; SCHIRLO, 2014, p. 38). No processo de aprendizagem, os conceitos subsunçores devem ser identificados previamente e, após sua interação com o novo conhecimento, podem resultar em um novo subsunçor, ou seja, o novo conhecimento pode servir como ancoradouro para um próximo conceito.

Para ser significativa, a aprendizagem deve acontecer de forma não arbitrária e não literal, ou seja, estar ligada a conceitos claros e específicos já existentes na estrutura 
cognitiva do aprendiz, não apenas a palavras ou termos, a fim de que possam ser expandidos. Isso significa que não pode haver exclusividade no uso do conhecimento, pois, nesse caso, este se tornaria refém do contexto em que foi aprendido.

$\mathrm{Na}$ falta de subsunçores, isto é, quando o novo conhecimento não encontra conhecimentos anteriores na estrutura cognitiva para se ancorar, pode-se lançar mão de meios e/ou materiais para desenvolvê-los. Nessa perspectiva, é possível recorrer a organizadores prévios, ou seja, a materiais que organizam a estrutura cognitiva de modo que nela seja estabelecido um novo subsunçor capaz de ancorar o novo conhecimento a ser apresentado. Esses organizadores devem ser utilizados de forma preliminar, do mesmo modo que precisam ser apresentados em um nível mais alto de abstração em relação ao material que será estudado.

Há dois tipos de organizadores prévios: os expositivos e os comparativos. O uso do primeiro tipo é recomendado quando o aprendiz não tem subsunçores sobre o assunto que será estudado, isto é, quando o material de aprendizagem não Ihe é familiar. Dessa forma, supostamente, o material deve promover uma ancoragem ideacional em termos familiares ao aprendiz (MOREIRA, 2018, p. 11). Quando o novo material é relativamente familiar para o aprendiz, recomenda-se a utilização de um organizador comparativo, que o ajudará a integrar novos conhecimentos à estrutura cognitiva e, ao mesmo tempo, a discriminá-los de outros conhecimentos já existentes nessa estrutura que, embora essencialmente diferentes, podem ser confundidos (MOREIRA, 2018).

Além dos organizadores prévios, Ausubel menciona a existência dos pseudoorganizadores, materiais introdutórios destinados a facilitar a aprendizagem de vários tópicos. Exatamente por serem mais genéricos e servirem a uma gama maior de tópicos, eles se diferenciam dos organizadores prévios, que são destinados a facilitar a aprendizagem de um tópico específico. Moreira (2012) menciona como exemplo o estudo de Souza (1980), em que foram utilizados 13 pseudo-organizadores prévios com o objetivo de facilitar a aprendizagem de Eletricidade e Magnetismo. Segundo o autor:

O primeiro desses textos servia como pseudo-organizador para a primeira unidade, mas se destinava também a funcionar como pseudoorganizador prévio para todo o curso. Cada um desses materiais era apresentado como "Introdução" do guia de estudos da unidade correspondente (MOREIRA, 2012, p. 4, tradução nossa).

Ainda de acordo com a TAS, qualquer aprendizagem pode se tornar significativa a partir do momento em que for ancorada em um subsunçor. No entanto, alguns fatores precisam ser levados em conta para que o processo seja bem-sucedido. Há condições essenciais que estruturam a aprendizagem significativa, que são a disposição do sujeito para aprender e a adequação do material a ser utilizado. Tendo em vista que o aprendiz precisa estar disposto a aprender significativamente, é fundamental que ele se sinta motivado e interessado nessa forma de aprendizagem, pois, caso contrário, irá aprender mecanicamente através da memorização, dando-se por satisfeito. Ainda, é imprescindível que esse material, além de relacionável com a estrutura cognitiva, mostre-se "potencialmente significativo", como denomina Ausubel.

Ligado às etapas do processo da aprendizagem significativa, surge o princípio da "diferenciação progressiva", que, segundo Moreira e Masini (2006), constitui-se de conceitos mais gerais, abordados inicialmente, para, no decorrer do processo, ocorrer a integração de elementos mais específicos. Tal descrição corrobora a premissa de Ausubel, no sentido de 
que é mais fácil compreender elementos a partir de um todo do que estabelecer um todo a partir de fragmentos. Em outras palavras, primeiro aprende-se o geral para depois detalhar/analisar elementos menores e mais complexos.

Após a diferenciação progressiva, acontece a chamada "reconciliação integrativa", momento em que as ideias passam a se relacionar a partir de similaridades e diferenças entre conceitos. Dito de outro modo, os novos conhecimentos estabelecem vínculos e ancoragens com diversos elementos presentes na estrutura cognitiva do aprendiz, e esta pode se reorganizar e adquirir novos significados.

Quando a nova informação se relaciona com o conceito subsunçor, já presente na estrutura cognitiva, ocorre o processo denominado de "assimilação", que, por sua vez, é um produto dos dois conceitos. Ou seja, o subsunçor e o novo conhecimento se modificam ao longo do processo de aprendizagem, tornando-se mais amplos que os conceitos individuais. Assim, destaca-se que esses conceitos modificados interagem de forma que apenas podem resultar em uma aprendizagem significativa a partir do ciclo de aprendizagem experiencial, sendo, para isso, compreendidos juntos e estruturando-se, aos poucos, até que, consequentemente, em determinado momento se tornem um único conceito capaz de gerar um novo subsunçor.

De acordo com essa lógica, portanto, a identificação de uma aprendizagem significativa só é possível quando o sujeito emprega o novo conhecimento fora do contexto em que o aprendeu, remodelando ou ressignificando os saberes que se tornarão mais importantes e atuarão como novos subsunçores ou conhecimentos prévios, capazes de dar significado ao estudo de novos conceitos.

Tendo presentes as premissas da TAS como elementos estruturantes, a investigação apresentada neste texto desenvolveu-se tomando como base a metodologia descrita na próxima seção.

\section{A pesquisa}

Conforme Triviños (1987, p. 128-130), uma pesquisa de natureza qualitativa apresenta cinco caraterísticas fundamentais:

$\left.1^{10}\right)$ tem o ambiente natural como fonte direta dos dados e o pesquisador como instrumento-chave;

$\left.2^{\circ}\right)[. .$.$] é descritiva;$

30) Os pesquisadores qualitativos estão preocupados com o processo e não simplesmente com os resultados e o produto;

$\left.4^{\circ}\right)$ Os pesquisadores qualitativos tendem a analisar seus dados indutivamente;

$\left.5^{\circ}\right)$ O significado é a preocupação essencial na abordagem qualitativa [...].

Nesse sentido, elegeu-se a abordagem qualitativa, tendo em vista que a investigação não se preocupou com a quantificação dos trabalhos que utilizam organizadores prévios, e sim com a identificação de quais materiais - e de que forma - estão sendo utilizados no processo de ensinar Física no âmbito brasileiro.

Para tanto, recorreu-se a uma pesquisa de natureza bibliográfica, selecionando um conjunto de periódicos brasileiros disponíveis on-line e que integram o Sistema WebQualis da Coordenação de Aperfeiçoamento de Pessoal de Nível Superior (Capes), estratos A1 e 
A2, publicados no período compreendido entre o ano de 2008 e o primeiro semestre de 2019. Optou-se pelo WebQualis como fonte de dados por se tratar de uma pesquisa que investiga a produção brasileira na área e também porque o sistema reúne os periódicos de maior circulação acadêmica no país. Das 48 áreas em que ele está estruturado, a de Ensino é a que abarca o maior número de periódicos no campo do Ensino de Ciências e Matemática, tendo em seus artigos parte significativa das produções nacionais em termos dos resultados decorrentes de teses e dissertações. Todos esses fatores o tornam relevante para um estudo que busca discutir o ensino de Física.

Para identificar os artigos que compuseram o corpus da pesquisa, procedeu-se à busca nesses periódicos de trabalhos que apresentassem a expressão "organizador prévio" no título, nas palavras-chave e/ou no resumo.

Assim, como se percebe nos dados contidos no Quadro 1, seis artigos foram selecionados para investigação.

Quadro 1 - Relação dos artigos que constituíram o corpus da investigação.

\begin{tabular}{|c|c|c|c|c|}
\hline Periódico & Estrato & Título do artigo & Autor(es) & Ano \\
\hline Revista Ensaio & A1 & $\begin{array}{c}\text { Organizadores prévios para } \\
\text { aprendizagem significativa em Física: } \\
\text { o formato curta de animação }\end{array}$ & $\begin{array}{l}\text { Rafael João Ribeiro } \\
\text { Sani de Carvalho } \\
\text { Rutz da Silva } \\
\text { André Koscianski }\end{array}$ & 2012 \\
\hline Acta Scientiae & $\mathrm{A} 2$ & $\begin{array}{c}\text { Uso de organizadores prévios na } \\
\text { aprendizagem significativa do } \\
\text { eletromagnetismo }\end{array}$ & $\begin{array}{l}\text { Roberto Luiz de } \\
\text { Azevedo }\end{array}$ & 2013 \\
\hline Revista ARETÉ & A2 & $\begin{array}{c}\text { História das Ciências e TIC: } \\
\text { organizador prévio no processo } \\
\text { ensino-aprendizagem de Física na } \\
\text { Amazônia }\end{array}$ & $\begin{array}{c}\text { Ana Paula Sá } \\
\text { Menezes } \\
\text { Josefina Barrera } \\
\text { Kalhil } \\
\end{array}$ & 2009 \\
\hline Acta Scientiae & $\mathrm{A} 2$ & $\begin{array}{c}\text { Animações interativas como } \\
\text { organizadores prévios para o Ensino } \\
\text { da Física }\end{array}$ & $\begin{array}{l}\text { Waltrudes E. Sanches } \\
\text { Juliano Schimiguel }\end{array}$ & 2012 \\
\hline $\begin{array}{l}\text { Caderno } \\
\text { Brasileiro de } \\
\text { Ensino de } \\
\text { Física }\end{array}$ & $\mathrm{A} 2$ & $\begin{array}{l}\text { Simulação computacional aliada à } \\
\text { Teoria da Aprendizagem } \\
\text { Significativa: uma ferramenta para } \\
\text { ensino e aprendizagem do efeito } \\
\text { fotoelétrico }\end{array}$ & $\begin{array}{l}\text { Stenio Octávio de } \\
\text { Oliveira Cardoso } \\
\text { Adriana Gomes } \\
\text { Dickman }\end{array}$ & 2012 \\
\hline $\begin{array}{l}\text { Caderno } \\
\text { Brasileiro de } \\
\text { Ensino de } \\
\text { Física }\end{array}$ & $\mathrm{A} 2$ & $\begin{array}{c}\text { Física em ação através de tirinhas e } \\
\text { histórias em quadrinhos }\end{array}$ & $\begin{array}{c}\text { Moisés Lobo } \\
\text { D'Almada Alves } \\
\text { Pereira } \\
\text { Laudileni Olenka } \\
\text { Paloma Emanuelle } \\
\text { Duarte Fernandes } \\
\text { Oliveira }\end{array}$ & 2016 \\
\hline
\end{tabular}

Fonte: Dados da pesquisa, 2019.

Após a leitura dos artigos, adotando como principal critério uma análise descritiva das investigações, buscou-se identificar os materiais utilizados como organizadores prévios e forma como se deu a sua aplicação no processo de ensinar Física. Ainda, procurou-se evidenciar as principais áreas dessa ciência em que os materiais foram empregados. 


\section{Resultados e discussão}

A análise dos trabalhos partiu de duas categorias, uma voltada a evidenciar os materiais que estão sendo utilizados como organizadores prévios e a outra com foco na forma como eles têm sido utilizados no processo de ensino de Física.

\section{Materiais utilizados}

De acordo com Moreira (2008), os organizadores prévios são compreendidos como um recurso instrucional potencialmente facilitador da aprendizagem significativa, no sentido de servirem de ponte cognitiva entre os novos conhecimentos e aqueles já existentes na estrutura cognitiva do aprendiz (MAZINI; MOREIRA, 2008, p. 17). Assim, esta categoria será dedicada a apresentar os materiais utilizados como organizadores prévios nos seis trabalhos analisados.

Como evidenciam os dados contidos no Quadro 2, os recursos tecnológicos são os materiais mais utilizados pelos pesquisadores para promover a ligação dos conceitos subsunçores com os objetos de estudo.

Quadro 2 - Materiais utilizados como organizadores prévios.

Materiais utilizados como organizadores prévios

Curta de animação

Vídeos e texto com explicações conceituais

Vídeos feitos com software Windows Movie Maker

Animações interativas computacionais

Leitura de textos e artigos científicos

Oficina didática

História em quadrinhos e tirinhas

Fonte: Dados da pesquisa, 2019.

Nessa direção, o trabalho de Ribeiro, Silva e Koscianski (2012) apresenta a construção e a aplicação de um curta de animação como organizador prévio para o estudo do conceito de momento de uma força no ensino médio. O curta, intitulado Momento de uma força, apresenta:

a história de uma personagem em dificuldade para trocar o pneu furado de sua caminhonete. O protagonista é um senhor de cabelos brancos e franzino que, logo após retirar a caminhonete da garagem de sua casa, percebe que um dos pneus está furado. Então, retira com calma o equipamento necessário para troca do pneu, como chave de roda, macaco e pneu estepe. Surge um problema quando, mesmo com muita força e várias tentativas diferentes, não consegue afrouxar o parafuso da roda usando uma chave convencional. Em outra cena, um passarinho começa a pular nas hastes de uma antena de TV sobre o telhado. O passarinho quebra as hastes quando pula mais próximo das suas extremidades. A personagem principal observa a ação do passarinho e estende o tamanho da chave de roda encaixando nela um cano. Quando finalmente consegue retirar o parafuso, o passarinho o rouba e voa para longe, fechando o vídeo (RIBEIRO; SILVA; KOSCIANSKI, 2012, p. 175). 
A criação do curta considerou as três etapas sugeridas por Millerson (2001) - préprodução, produção e pós-produção -, e sua implementação ocorreu junto a um grupo de estudantes do ensino médio, seguindo as fases do método organizador prévio de Joyce e Weiel (1996). Na análise dos autores da pesquisa, o curta de animação apresentou características relevantes e suficientes para validar a sua utilização como organizador prévio (RIBEIRO; SILVA; KOSCIANSKI, 2012, p. 181).

No trabalho intitulado "Simulação computacional aliada à Teoria da Aprendizagem Significativa: uma ferramenta para o ensino e aprendizagem do efeito fotoelétrico", Cardoso e Dickman (2012) relatam o processo de elaboração e aplicação de uma sequência de atividades que se apoia no uso de simulações computacionais para o ensino do fenômeno luminoso. Entre as atividades apresentadas, os autores propõem dois vídeos que mostram a parte histórica do fenômeno do efeito fotoelétrico como instrumentos voltados a realçar os subsunçores existentes na estrutura cognitiva do aprendiz, levando-o a lembrar de fatos presentes no cotidiano e que podem servir de ponte para a compreensão dos conceitos. Conforme explicitam os pesquisadores, o primeiro vídeo apresenta aparelhos e tecnologias atuais que funcionam graças ao efeito fotoelétrico; e o segundo explica, por meio de animações, a ocorrência do fenômeno, bem como o comportamento dual da luz. No entendimento dos pesquisadores, as informações contidas nesses vídeos podem ser significativas para a assimilação dos conceitos mais específicos e menos inclusivos que serão estudados nas demais atividades propostas (CARDOSO; DICKMAN, 2012).

Os autores relatam que, na tentativa de obedecer à ordem de inclusividade de conceitos, após a exibição dos vídeos, os participantes foram orientados a ler um texto que aborda o efeito fotoelétrico de forma conceitual e contextualizada. A conclusão do trabalho indica que a exibição dos vídeos e a leitura do texto proporcionaram aos estudantes subsunçores importantes para o entendimento do que estava sendo estruturado (CARDOSO; DICKMAN, 2012).

Vídeos feitos com o software Windows Movie Maker sobre a vida de físicos importantes para a área foram os instrumentos utilizados por Menezes e Kalhil (2009) como organizadores prévios num trabalho que apresenta um estudo bibliográfico sobre o uso de tecnologias de informação e comunicação no ensino de Física. De acordo com os autores, apresentar os cientistas por de trás das fórmulas é uma das estratégias possíveis para dar significado às aulas de Física (MENEZES; KALHIL, 2009, p. 148).

Conforme Menezes e Kalhil (2009), essa técnica favorece o desenvolvimento da atividade intelectual independentemente das diferenças individuais dos alunos, uma vez que estimula a formação de elementos teóricos e os processos lógicos do conhecimento. Assim, salientam que esses materiais contribuem para a ligação dos conhecimentos prévios aos estudos posteriores.

Em outro trabalho, Sanches e Schimiguel (2012) apresentam uma investigação que visou verificar se o uso de animações interativas computacionais como organizadores prévios pode favorecer o processo de ensino e aprendizagem dos conceitos de energia mecânica. Segundo os autores, a pesquisa compreendeu dois grupos de estudantes do ensino médio, um experimental e outro controle. Para o grupo experimental, adotou-se uma animação interativa como organizador prévio ao estudo dos conceitos de energia mecânica, e para o grupo controle, o desenvolvimento dos assuntos ocorreu com aulas expositivas, sem o recurso da animação. Os grupos foram submetidos a um pré-teste para 
averiguar os conhecimentos acerca dos conceitos relacionados à energia mecânica e a um pós-teste que buscou evidenciar o progresso após a intervenção didática.

A animação selecionada para a pesquisa foi desenvolvida em uma linguagem visual basic, no ambiente Visual Basic 6 da Microsoft, e elaborada com base nos conceitos da área investigada. Nela, os estudantes podiam simular os processos de transformação de energia que ocorrem em um bate-estaca. Nessa etapa, o grupo assistiu a um pequeno vídeo caseiro que mostra uma descida realizada em uma grande montanha-russa, com o propósito de despertar o interesse para o conteúdo que seria tratado posteriormente e, com isso, criar um ambiente de motivação, facilitando a conexão dos novos conceitos à estrutura cognitiva. Em seguida, ainda no mesmo espaço físico, foi apresentada ao grupo a animação interativa utilizada na pesquisa (SANCHES; SCHIMIGUEL, 2012, p. 447).

Os resultados da pesquisa demonstram que o grupo experimental apresentou um ganho em escores de acerto no pós-teste superior ao do grupo controle, levando os pesquisadores a concluir que as animações interativas, na função de organizadores prévios, podem favorecer os processos de ensino e aprendizagem dos conceitos de energia mecânica (SANCHES; SCHIMIGUEL, 2012, p. 453).

Visando proporcionar situações metodológicas que levem os estudantes a desenvolver aprendizagens significativas sobre o eletromagnetismo, Azevedo (2013) propõe a leitura de artigos científicos e uma oficina pedagógica como organizadores prévios para estudos da área. Nesse sentido, apresenta um trabalho de pesquisa que buscou perceber se a utilização desses recursos é capaz de ativar e organizar a estrutura cognitiva de estudantes de terceira série do ensino médio para estudos futuros.

A metodologia de pesquisa adotada no trabalho estruturou-se em quatro etapas. $\mathrm{Na}$ primeira, aplicou-se um pré-questionário; na segunda, efetuou-se a leitura de textos históricos e científicos relacionados com o eletromagnetismo; na terceira, os estudantes participaram de uma oficina didática; e, na última, responderam a um pós-questionário.

As atividades realizadas nas etapas dois e três foram consideradas pelo autor como tendo a função de organizadores prévios. Para a etapa dois, foram escolhidos um texto histórico que relata a experiência de Oersted e um artigo científico pertinente ao estudo do eletromagnetismo (AZEVEDO, 2013, p. 310). Após a leitura desses textos, na terceira etapa da pesquisa, os estudantes participaram de uma oficina didática, na qual, de posse dos conhecimentos e conceitos adquiridos, reestruturados ou modificados, passaram a construir um motor elétrico a partir de peças pré-montadas e de um roteiro guia.

De acordo com o autor, por meio das respostas dos estudantes, percebeu-se que houve tanto a incorporação de ideias novas às suas estruturas cognitivas como uma mudança em suas preconcepções, que se transformaram em ideias mais estáveis e coerentes (AZEVEDO, 2013, p, 318). Assim, concluiu-se, no trabalho, que a utilização desses materiais como organizadores prévios se mostrou eficaz na manipulação da estrutura cognitiva dos estudantes para a suscitação e/ou sedimentação das ideias esteios, favorecendo uma aprendizagem significativa de conceitos de eletromagnetismo.

Por fim, Pereira, Olenka e Oliveira (2016) apresentam um trabalho que visou analisar a viabilidade da utilização de tirinhas e história em quadrinhos como organizadores prévios no ensino de Física. O propósito de utilizar esses materiais em aulas de Física consiste, segundo os autores, em motivar os estudantes e, assim, estabelecer a ponte entre os conhecimentos subsunçores presentes em sua estrutura cognitiva e os assuntos de 
velocidade, aceleração, queda livre e lançamento vertical (PEREIRA; OLENKA; OLIVEIRA, 2016).

A metodologia utilizada teve um enfoque prático-metodológico com objetivo exploratório, fazendo uso da riqueza visual desses materiais para facilitar a visualização dos conceitos abstratos da Física. Nesse sentido, os autores relatam que:

As tirinhas foram utilizadas como material introdutório, como conteúdo atrativo e potencialmente significativo, facilitador da preparação de subsunçores (no início dos conteúdos), sempre levando em consideração a realidade dos alunos e a cultura deles. Essas tirinhas iniciais foram abordadas de modo conceitual, evitando-se a presença de equações. Utilizou-se também o método da tempestade cerebral, para estimular a participação de todos e sondar o conhecimento prévio. Para evitar constrangimentos as opiniões foram registradas em pequenos pedaços de papel e armazenadas numa caixinha. Assim cada aluno contribui com um conceito ou uma ideia, havendo uma discussão em torno do conceito central. Essa atividade, além de ser útil para ter uma noção do conhecimento da turma, ainda serve para a formulação do conceitochave, com base nas principais sugestões conceituais concedidas pelos próprios alunos (PEREIRA; OLENKA; OLIVEIRA, 2016, p. 904).

Participaram da pesquisa dois grupos de estudantes, um experimental e outro controle. Ambos estudaram os conceitos selecionados, porém, enquanto o grupo experimental fez uso de uma abordagem que continha tirinhas e histórias em quadrinhos como organizadores prévios, o grupo controle realizou o estudo dos conceitos com base em uma metodologia tradicional (PEREIRA; OLENKA; OLIVEIRA, 2016, p. 905).

A análise dos resultados demonstrou que os estudantes do grupo experimental tiveram um desempenho melhor que os que formavam o grupo controle. Isso indica que as histórias em quadrinhos e as tirinhas são meios interessantes e facilitadores de ensino, revelando a potencialidade de articular os conhecimentos iniciais dos estudantes na direção de uma aprendizagem significativa de conceitos físicos (PEREIRA; OLENKA; OLIVEIRA, 2016).

Moreira (2018, p. 3) salienta que os organizadores prévios são elementos organizacionais inclusivos que levam em consideração e põem em destaque o conteúdo específico do novo material de estudo. Nesse sentido, a análise dos trabalhos selecionados para esta investigação evidencia que, independentemente do material utilizado, as metodologias de ensino que envolvem o uso de organizadores prévios tendem a alcançar sucesso na promoção de aprendizagens significativas nos estudos de conceitos físicos.

\section{Utilização no ensino de Física}

Esta categoria busca avaliar se os materiais contidos nos trabalhos selecionados para a investigação constituem-se de organizadores prévios comparativos ou expositivos.

Como salientado na fundamentação teórica, quando se almeja a aprendizagem de um conceito relativamente familiar ao estudante, os materiais que estabelecem a ponte entre os conhecimentos anteriores e o novo assunto referem-se ao organizador prévio classificado como comparativo. Na concepção de Moreira (2018, p. 19), estes devem ser usados para integrar e discriminar as novas informações e conceitos, ideias ou proposições, basicamente similares, já existentes na estrutura cognitiva. 
Dos trabalhos aqui analisados, metade utiliza os organizadores prévios de forma comparativa. Isto é, em três artigos os autores propõem as atividades antes de iniciar a discussão de conteúdos já existentes na estrutura cognitiva dos estudantes e, portanto, deles conhecidos.

No trabalho de Pereira, Olenka e Oliveira (2016), os materiais utilizados como organizadores prévios destinam-se à discussão dos conceitos básicos de movimentos para estudantes da primeira série do ensino médio. Considerando que esses conceitos são assuntos discutidos na disciplina de Ciências ao longo do ensino fundamental e que cotidianamente os estudantes experienciam situações envolvendo movimentos, conclui-se que o tema já está incorporado em sua estrutura cognitiva, e, dessa forma, os materiais selecionados no trabalho visaram estabelecer sua ligação com o novo conhecimento.

A mesma estratégia foi adotada por Sanches e Schimiguel (2012) e Ribeiro, Silva e Koscianski (2012), que abordaram os conceitos de energia mecânica e momento de uma força, respectivamente. Nos dois trabalhos, os materiais utilizados como organizadores prévios são implementados junto a um grupo de estudantes da terceira série do ensino médio que apresentam conhecimentos anteriores sobre o tema.

Nos trabalhos de Cardoso e Dickman (2012), de Azevedo (2013) e de Menezes e Kalhil (2009), os assuntos de estudo não eram familiares aos estudantes participantes das propostas. Dessa forma, os materiais utilizados como organizadores prévios, classificados como expositivos, buscaram estabelecer conceitos subsunçores na estrutura cognitiva dos aprendizes.

Como mencionado anteriormente, efeito fotoelétrico foi o conceito abordado no trabalho de Cardoso e Dickman (2012). De acordo com os autores, o fenômeno é abstrato e de difícil visualização, e os materiais utilizados como organizadores prévios podem ser uma ferramenta na construção, ilustração e relação entre as variáveis que dão significado aos conteúdos associados ao efeito. Para eles, as imagens e os símbolos produzidos pela informática podem proporcionar, em diferentes níveis, um ganho cognitivo. Paralelamente, a simulação irá fornecer, de maneira dinâmica, imagens sobre o fenômeno, variáveis que podem modificar o resultado apresentado pela simulação e, também, realçar os principais aspectos, bem como as propriedades sobre o seu acontecimento (CARDOSO; DICKMAN, 2012, p. 898).

No trabalho de Azevedo (2013), abordam-se os conceitos relativos ao eletromagnetismo com estudantes de terceira série do ensino médio. Embora o grupo de sujeitos que participaram do trabalho já tivesse estudado uma grande gama de conceitos físicos, os assuntos relacionados com força magnética e indução eletromagnética, temas da proposta, não eram de seu conhecimento. Nessa perspectiva, segundo o autor, os materiais utilizados como organizadores prévios objetivaram organizar a estrutura cognitiva dos alunos para aquilo que seria estudado futuramente e balizaram as atividades da oficina (força magnética) que foi realizada após o cumprimento de outros estágios (leitura dos textos de indução eletromagnética) (AZEVEDO, 2013, p. 307).

Por fim, o trabalho de Menezes e Kalhil (2009) apresenta vídeos sobre a vida de pessoas importantes da Física como organizadores prévios ao estudo da disciplina para estudantes do nono ano do ensino fundamental. Da forma como o ensino de Física está organizado atualmente na educação básica, é nessa série que se iniciam mais organizadamente os estudos da área. Logo, esses vídeos, na concepção dos autores, 
podem servir para formar na mente dos estudantes as noções básicas para o prosseguimento da aprendizagem dos conceitos físicos (MENEZES; KALHIL, 2009).

De acordo com Moreira (2013), existem muitas possibilidades de utilização dos organizadores prévios. Porém, segundo o autor, a condição essencial é que precedam a apresentação do material de aprendizagem e que sejam mais abrangentes, gerais e inclusivos do que ele (MOREIRA, 2013, p. 14). Nesse sentido, os resultados demonstram que os organizadores prévios têm sido utilizados para estabelecer a ponte entre os conceitos subsunçores presentes na estrutura cognitiva do aprendiz e, também, com o intuito de construir subsunçores relevantes à aprendizagem de novos conhecimentos antes de prosseguir.

\section{Considerações finais}

O cenário atual demonstra a necessidade de cidadãos críticos, reflexivos, ativos e com conhecimentos diversos para o enfrentamento das situações que uma sociedade em constante transformação exige. Dessa forma, o processo de ensinar e aprender deve promover aprendizagens que sejam verdadeiramente significativas para aqueles que frequentam os bancos escolares.

A TAS tem demonstrado que a ligação entre os conceitos prévios dos estudantes e os novos conhecimentos é promotora de aprendizagens sólidas, duradouras e que possibilitam ao aprendiz transpor o que estuda nos bancos escolares para novos contextos. Na compreensão de Moreira (2013), essa forma de aprendizagem é favorecida com a utilização de materiais denominados "organizadores prévios", que visam ajudar o aprendiz a perceber que novos conhecimentos estão relacionados a ideias apresentadas anteriormente, a subsunçores que existem em sua estrutura cognitiva prévia.

De acordo com a investigação aqui apresentada, os recursos tecnológicos são os mais utilizados no ensino de Física para promover a ponte cognitiva entre os conhecimentos prévios e os novos conhecimentos. Além desses, histórias em quadrinhos, tirinhas, oficinas didáticas e textos também têm sido utilizados, resultados que vão ao encontro da visão de Moreira (2013, p. 14), no sentido de que os organizadores prévios podem consistir em um enunciado, uma pergunta, uma situação-problema, uma demonstração, um filme, uma leitura introdutória, uma simulação. Quanto à forma como são utilizados, percebeu-se a intenção de mostrar, por meio deles, a relacionalidade e a discriminabilidade entre novos conhecimentos e conhecimentos já existentes, bem como de suprir a deficiência ou ausência dos subsunçores.

Ressalta-se, por fim, que todas as experiências relatadas e analisadas neste trabalho realçam a melhora da aprendizagem com a utilização de organizadores prévios no ensino de Física. Dessa forma, acredita-se que mais estudos sobre o tema podem ser estruturados visando à promoção de aprendizagens significativas na área. 


\section{Referências}

AUSUBEL, David Paul; NOVAK, Joseph Donald; HANESIAN, Helen. Educational psychology: a cognitive view. 2. ed. New York: Holt Rinehart and Winston, 1978.

AZEVEDO, Roberto Luiz de. Uso de organizadores prévios na aprendizagem significativa do eletromagnetismo. Acta Scientiae, v. 15, n. 2, p. 304-320, maio/ago. 2013.

CARDOSO, Stenio Octávio de Oliveira; DICKMAN, Adriana Gomes. Simulação computacional aliada à Teoria da Aprendizagem Significativa: uma ferramenta para ensino e aprendizagem do efeito fotoelétrico. Caderno Brasileiro de Ensino de Física, v. 29, n. Especial 2, p. 891-934, out. 2012.

CHAVES, Alaor; SHELLARD, Ronald Cintra (Eds.). Física para o Brasil: pensando o futuro. São Paulo: Sociedade Brasileira de Física, 2005.

CUTRER, William B.; CASTRO, Danny; ROY, Kevin M.; TURNER, Teri L. Use of an expert concept map as an advance organizer to improve understanding of respiratory failure. Medical Teacher, v. 33, n. 12, p. 1018-1026, 2012.

DARROZ, Luiz Marcelo; TREVISAN, Thais Lorençato; ROSA, Cleci Teresinha Werner da. Estratégias de aprendizagem: caminhos para o sucesso escolar. Amazônia: Revista de Educação em Ciência e Matemáticas, v. 14, n. 29, p. 93-109, jan/jun. 2018.

JOYCE, Bruce R; WEIL, Marsha. Models of teaching. 5. ed. Boston: Massachusetts: Allyn and Bacon, 1996.

MASINI, Elcie Aparecida Fortes Salzano; MOREIRA, Marco Antonio. Aprendizagem significativa: condições para ocorrência e lacunas que levam a comprometimentos. São Paulo: Vetor, 2008.

MENEZES, Ana Paula Sá; KALHIL, Josefina Barrera. História das Ciências e TIC: organizador prévio no processo ensino-aprendizagem de Física na Amazônia. ARETÉ - Revista Amazônica de Ensino de Ciências, v. 2, n. 3, p. 144-150, 2009.

MILLERSON, Gerald. Video production handbook. 3. ed. Great Britain: Focal Press, 2001.

MOREIRA, Marco Antonio. Teorias de aprendizagem. São Paulo: EPU, 1999.

MOREIRA, Marco Antonio. Aprendizagem significativa, organizadores prévios, mapas conceituais, diagramas $V$ e unidades de ensino potencialmente significativas. Material de apoio para o curso Aprendizagem Significativa no Ensino Superior: Teorias e Estratégias Facilitadoras. PUCPR, 2012-2013. Disponível em: https://www.passeidireto.com/arquivo/65504286/ausubel-aprendizagem-significativaorganizadores-previos-e-mapas-conceituais-moreira. Acesso em: 17 out. 2019.

MOREIRA, Marco Antonio. Organizadores Previos y Aprendizaje Significativo. Disponível em: http://moreira.if.ufrgs.br/ORGANIZADORESesp.pdf. Acesso em: 06 ago. 2020.

MOREIRA, Marco Antonio. Uma análise crítica do ensino de Física. Estudos Avançados, São Paulo, v. 32, n. 94, set./dez. 2018.

MOREIRA, Marco Antonio; MASINI, Elcie Aparecida Fortes Salzano. Aprendizagem significativa: a teoria de David Ausubel. 2. ed. São Paulo: Centauro, 2006. 
PEREIRA, Moisés Lobo D'Almada Alves; OLENKA, Laudileni; OLIVEIRA, Paloma Emanuelle Duarte Fernandes. Física em ação através de tirinhas e histórias em quadrinhos. Caderno Brasileiro de Ensino de Física, v. 33, n. 3, p. 896-926, dez. 2016.

RIBEIRO, João Rafael; SILVA, Sani de Carvalho Rutz da; KOSCIANSKI, André. Organizadores prévios para aprendizagem significativa em Física: o formato curta de animação. Revista Ensaio, Belo Horizonte, v. 14, n. 3, p. 167-183, set./dez. 2012.

SANCHES, Waltrudes Everton; SCHIMIGUEL; Juliano. Animações interativas como organizadores prévios para o ensino da Física. Acta Scientiae, v. 14, n. 3, p. 439-455, set./dez. 2012.

SILVA, Sani de Carvalho Rutz da; SCHIRLO, Ana Cristina. Teoria da Aprendizagem Significativa de Ausubel: reflexões para o ensino de Física ante a nova realidade social. Imagens da Educação, v. 4, n. 1, p. 36-42, 2014.

STONE, Carol Leth. A Meta-Analysis of Advance Organizer Studies. Journal Reading World, v. 22, n. 1, p. 194-199, 2015.

TRIVIÑOS, Augusto Nibaldo Silva. Introdução à pesquisa em Ciências Sociais: a pesquisa qualitativa em Educação. São Paulo: Atlas, 1987. 